\title{
A TEORIA DOS CAMPOS MÓRFICOS E A EMERGÊNCIA DA VISÃo SISTÊMICA SOBRE O EQUILÍBRIO NO MEIO AMBIENTE
}

\author{
Carlos Hiroo Saito ${ }^{1}$ \\ Ivete Teresinha Saito ${ }^{2}$ \\ Ivana de Campos Ribeiro ${ }^{3}$
}

\begin{abstract}
Resumo
Acredita-se que o conhecimento dos processos ecológicos é fundamental e, sua ausência seria a causa primordial de comportamentos danosos ao ambiente. Percebe-se a necessidade de equilibrar o aprendizado de conceitos científicos sobre processos da natureza com a mudança de percepção e de valores na educação ambiental (EA). O objetivo deste trabalho é a avaliação dos resultados de uma experiencia de intervenção com 120 alunos entre 10 e 11 anos de idade, utilizando um jogo lúdico para tratar do conceito de equilíbrio dinâmico na natureza. Os resultados apontaram a antecipação do conceito que seria trabalhado posteriormente. A mudança de percepção dos processos, aliada ao desenvolvimento de valores por meio de jogos educativos, pode ser um caminho produtivo para a realização de uma EA mais profunda, buscando seu sustentáculo em bases transdisciplinares, dentre as quais a teoria dos campos mórficos pode ser um lastro forte para compreender os processos de desenvolvimento de um novo saber ecocêntrico.
\end{abstract}

Palavras-chave: Educação ambiental. Valores. Campos mórficos.

\section{THE THEORY OF THE MORPHIC FIELDS AND THE EMERGENCE OF THE SYSTEMIC VISION ON THE BALANCE IN ENVIRONMENT}

\section{Abstract}

It is believed that knowledge of ecological processes is fundamental, and its absence would be the primary cause of harmful behavior to environment. The need to balance the learning of scientific concepts about processes in nature through the change of perception and values in Environmental Education. This study aims to evaluate the results of an intervention experience with 120 students between 10 and 11 years old, using a playful game to deal with the concept of dynamic balance in nature. The results pointed to the anticipation of the concept that would be worked on later. The change in perception of processes, together with the development of values through educational games, can be a productive path to achieve a deeper Environmental Education, seeking its support in transdisciplinary bases in which the theory of the morphic fields can be a strong basis to understand the processes for developing a new ecocentric knowledge.

Keywords: Environmental Education; Values; Morphic fields

\footnotetext{
${ }^{1}$ Doutor, Professor do Instituto de Ciências Biológicas da Universidade de Brasília. email: carlos.h.saito@hotmail.com

${ }^{2}$ Doutora, Técnica de Assuntos Educacionais da Universidade de Brasília, e Terapeuta Holística. email: ivete.saito@gmail.com

${ }^{3}$ Doutora em Ciências, Pesquisadora Colaboradora/UNICAMP, (Laboratório de Estudos do Estresse - LABEEST, IB, Laboratório de Biologia Estrutural e Funcional)
} 


\section{LA TEORÍA DE LOS CAMPOS MÓRFICOS Y LA EMERGENCIA DE LA VISIÓN SISTÉMICA SOBRE EL EQUILIBRIO EN EL MEDIO AMBIENTE}

\section{Resumen}

Se sabe que el conocimiento de los procesos ecológicos es fundamental, y su ausencia sería la causa primordial de conductas dañinas al ambiente. Es importante equilibrar el aprendizaje de conceptos científicos acerca de los procesos en la naturaleza con el cambio de percepción y de valores en la Educación Ambiental. El objetivo de este trabajo es evaluar los resultados de una experiencia de intervención con 120 alumnos entre 10 y 11 años, desde un juego lúdico para tratar del concepto de equilibrio dinámico en la naturaleza. Los resultados anticiparon un concepto que sería trabajado posteriormente. El cambio de percepción de los procesos, junto al desarrollo de valores por medio de juegos educativos, puede ser un camino productivo a la realización de una Educación Ambiental más profundizada, buscando sostenerse en bases transdisciplinares en las cuales la teoría de los campos mórficos puede ser muy importante en la comprensión de los procesos de desarrollo de un nuevo saber ecocéntrico.

Palabras clave: Educación Ambiental; valores; campos mórficos.

\section{Introdução}

A Lei Federal no 9.795/1999, que institui a Política Nacional de Educação Ambiental (PNEA), apresenta, em seu artigo $1^{\circ}$, a definição de educação ambiental (EA):

Entendem-se por Educação Ambiental os processos por meio dos quais o indivíduo e a coletividade constroem valores sociais, conhecimentos, habilidades, atitudes e competências voltadas para a conservação do meio ambiente, bem de uso comum do povo, essencial à sadia qualidade de vida e sua sustentabilidade (BRASIL, 1999).

Pode-se dizer que essa definição de EA deriva do disposto na Conferência de Tbilisi em 1977, que, em sua recomendação 1-C, afirma que

"um objetivo fundamental da Educação Ambiental é lograr que os indivíduos e a coletividade [...] adquiram os conhecimentos, os valores, os comportamentos e as habilidades práticas para participar responsável e eficazmente da prevenção e solução dos problemas ambientais, e da gestão da questão da qualidade do meio ambiente" (UNESCO, 1978).

Chamamos a atenção para um detalhe que surge no texto do artigo $1^{\circ}$ da nossa PNEA (BRASIL, 1999): a mudança na ordem, passando a figurar em primeiro lugar os valores, e não mais o conhecimento, como transcrito nas outras resoluções de conferências internacionais da área.

A partir desse reconhecimento, podemos depreender que EA não deve tratar apenas de aquisição de conhecimento, como se costuma depreender quando se direcionam atividades educativas para a transferência de informação. Em geral, acredita-se que o conhecimento dos processos é fundamental, decorrendo disso a noção de que a tarefa da EA é a de transmitir informação porque a falta dela seria a causa primordial de comportamentos danosos ao ambiente.

No entanto, a informação e o conhecimento, de forma isolada, não constituem garantia de uma efetiva mudança na relação homem-natureza. Saito, Gomes e Almeida (2011) demonstraram isso ao analisar um caso extremo de pesquisadores-sênior em ecologia deixando resíduos de pesquisa em área protegida. Da mesma forma, Tavares e Freire (2003) chegaram à conclusão de que a assimilação da informação não corresponde à mudança de atitudes. Forestell (1993, p. 277) 
já dizia que o conhecimento sem atitude não deixaria nenhum traço discernível de mudança, e que, por outro lado, atitude sem conhecimento também é indesejável, posto que este comportamento somente dura até que o modismo mude. Ou seja, não é internalizado.

Decorre desse entendimento o destaque dado à questão dos valores na PNEA: não basta querermos articular conhecimento e prática (atitudes, ação) se ambas não estiverem alicerçadas em um sistema de valores (RIBEIRO, 2018). Portanto, é preciso que, além de conhecimento e ação estarem articulados entre si, ambos estejam igualmente integrados a uma filosofia ambientalmente sensível (FORESTELL, 1993) ou compromissada com o respeito à natureza. Esse compromisso pró-ambiente representa uma predisposição para ações e atitudes a partir de uma convicção de que um modo específico de agir e o correspondente estado de espírito pró-ambiente são pessoal e socialmente preferíveis em relação a outro, de domínio e exploração da natureza (CADUTO, 1985; LEWIS; MANSFIELD; BAUDAINS, 2008).

Embora a definição de valores seja complexa, etimologicamente está relacionada ao antepositivo grego axios, dando origem a axiologia, área da filosofia dedicada aos valores humanos. De acordo com Pedro (2014), os valores referem-se ao que existe de comum e caracteriza o ser humano e não o indivíduo, tornando-se algo subjetivo ou arbitrário. Para a autora, a problemática dos valores está presente no mais íntimo de cada sujeito e constitui o fundamento da sua essência. Para Ribeiro $(2011 ; 2018)$, ao adentrar nas tradições orientais da educação em valores, aponta que estes são princípios morais e espirituais, coletivos e individuais, que fundamentam a consciência humana, não sendo ensinados, mas estimulados e resgatados de dentro do coração e estão presentes naturalmente em todos nós.

Apesar da discussão acumulada sobre a centralidade dos valores na EA, há lacunas no campo teórico-metodológico a serem preenchidas. Mais especificamente, a forma e o tipo de valores em questão e como desenvolvê-los em práticas de EA. Por outro lado, para quem desenvolve atividades práticas em EA, muitas vezes a falta de conexão com a teoria impossibilita uma análise mais aprofundada para extrair lições sobre a prática. Além disso, há a necessidade de se preocupar com o modo como valores são desenvolvidos e compartilhados numa coletividade.

Este último aspecto é o que tratamos, a partir de um relato de atividade feito há cerca de 30 anos, enquanto docentes de ensino fundamental, que somente agora, em um episódio isolado e incidental, parece adquirir relevância e capacidade analítica. A experiência foi desenvolvida no decorrer de algumas aulas sobre equilíbrio populacional no ensino de ciências ministradas para alunos de $5^{\mathrm{a}}$ e $6^{\mathrm{a}}$ séries de uma escola municipal na cidade do Rio de Janeiro, entre 1986 e 1988. Comentar uma atividade de 30 anos atrás pode trazer subsídios sobre o processo de ensino e aprendizagem, levando em conta possíveis mudanças neste espaço de tempo - tanto no despertar do interesse por um tema e pela atividade proposta como nos avanços da ciência, com seus novos conceitos e hipóteses para explicar comportamentos. Assim, defende-se a importância das atividades lúdicas - também nomeadas atividades anímicas (RIBEIRO, 2005) -, especialmente no que tange ao estado da arte da EA. Portanto, o foco do trabalho é a conexão teoria-prática sobre o desenvolvimento e compartilhamento de valores, à luz das discussões contemporâneas sobre valores e EA, especialmente a teoria dos campos mórficos, na qual encontramos ancoradouro recente para esta discussão, pois é comum que crianças detenham certos valores, e estes sejam perdidos na vida adulta (RIBEIRO; SCHWARTZ, 2017).

\section{Um episódio aparentemente insignificante}

Há 30 anos, em uma escola municipal do Rio de Janeiro (Escola Municipal Victor Hugo), uma experiência com quatro turmas de $5^{\mathrm{a}}$ série, cada uma com 30 alunos, na ocasião, despertou 
apenas curiosidade. Passados esses anos, à luz de novos estudos e, outros agora acreditados, podese perceber a importância dos resultados ali experienciados.

Lidando com estudantes de dez e 11 anos, o objetivo daquelas aulas de ciências era fazer os alunos entenderem o conceito de equilíbrio dinâmico na natureza, com a mútua regulação de população de predadores e presas e, ainda, que compreendessem como acontecia a ciclagem de nutrientes. Para tanto, um jogo proposto por Krasilchik (1983) - com adaptações - foi trabalhado com os alunos. Apesar da ludicidade envolvida no jogo, a estratégia de ensino-aprendizagem era voltada para o aspecto cognitivo, e o jogo seria tão somente um meio de coletar dados para discussão posterior em sala de aula.

A atividade prática consistia em dividir a turma em três grupos, aleatoriamente: um grupo representava as plantas, outro as lebres, e o terceiro representava as jaguatiricas. A divisão era feita de forma que proporcionalmente o grupo de plantas fosse maior do que o de lebres, e estes alunos, por sua vez, somariam um número maior de indivíduos que o total das jaguatiricas. Para distinguir os diferentes grupos, em algumas ocasiões chegou-se a confeccionar chapéus coloridos ou crachás, ou amaravam-se fitas coloridas, a depender do material disponível no momento. A cada rodada do jogo, era simulada uma geração de vida. O número de indivíduos de cada grupo (nível trófico) era contabilizado e registrado em uma tabela. Aqueles que representavam as plantas não podiam se mover e se posicionavam, em geral, na área externa, delimitando a área do jogo em um círculo.

Durante a rodada, que durava dez segundos, marcados pelo soar de um apito no início e no final, as jaguatiricas buscavam capturar (encostar com a mão) uma lebre, animal que correspondia ao seu alimento. As lebres, por sua vez, tinham que se alimentar das plantas sem serem devoradas pelas jaguatiricas. A lebre poderia, ainda, se proteger temporariamente da jaguatirica se agachando (simulando uma ação de se esconder na paisagem). Quando algum animal capturava seu alimento, o par ficava parado à espera do final da rodada. Assim, o jogo era uma grande brincadeira de pegapega, em que os animais se protegiam de seus predadores e buscavam, ao mesmo tempo, se alimentar. Para simular o ciclo de nutrientes na natureza e o sucesso reprodutivo, as lebres capturadas pelas jaguatiricas retornavam na rodada seguinte como jaguatiricas. Isso significava que as jaguatiricas bem-sucedidas tinham se alimentado, reproduzido e contribuído positivamente para o aumento de sua população. Da mesma forma, as lebres que conseguiam se alimentar com uma planta sem terem sido devoradas por uma jaguatirica, tiveram sucesso, enquanto as plantas capturadas voltavam na rodada seguinte como lebres. E assim sucessivamente. Ao final da rodada, todos os animais que não conseguiram se alimentar, bem como as plantas restantes, voltavam na rodada seguinte como plantas. Nesse contexto, isso representava o ciclo da natureza, no qual os seres vivos morrem, se decompõem e passam a integrar o rol de nutrientes disponíveis no solo para o crescimento e desenvolvimento das plantas.

Depois de várias rodadas, sempre registrando o número de plantas, lebres e jaguatiricas no início de cada rodada, eram reproduzidos os dados da tabela na lousa (quadro-negro) e, a partir deles, era construído um gráfico de variação da população de plantas, lebres e jaguatiricas ao longo do tempo. Normalmente, o que se observava era uma flutuação das três populações, que indicava um controle mútuo da população de presas e predadores, demonstrando, assim, o equilíbrio dinâmico da natureza. A análise do gráfico para compreensão da dinâmica de controle predadorpresa era o objetivo principal das aulas.

Porém, em um dos dias da realização dessa dinâmica, um fato inusitado ocorreu com uma das turmas: no meio da atividade, ainda na vigência de uma das rodadas do jogo, uma parte do grupo de alunos que representava a jaguatirica, quando foi capturar as lebres, voluntariamente recuou e se deixou "morrer de fome", pois não "devorou" seu alimento. Ficamos surpresos com o comportamento desse grupo. Ao perguntar sobre porque não tinham capturado a lebre, os alunos 
responderam: "Mas, claro, professor! Se a gente pegasse as lebres, não ia mais ter lebre na próxima rodada e todos morreriam de fome, e o jogo acabaria. Por isso, achamos melhor alguns morrerem de fome e ter lebres para continuar o jogo". Esse episódio foi considerado irrelevante à época, e só voltou à tona 30 anos depois porque ele permitia explicar a conexão teoria-prática no que se refere ao desenvolvimento de valores em EA.

\section{Insight, visão sistêmica e valores}

Pergunta-se então: qual o significado dessa atitude de preservação do alimento tomada pelo grupo? Afinal, o jogo era apenas uma atividade introdutória. Em nenhuma ocasião os conceitos envolvidos, tais como controle predador-presa, equilíbrio dinâmico e estabilidade foram trabalhados antes do jogo. Esses conceitos eram desenvolvidos depois da atividade, a partir da interpretação dos dados obtidos com a contagem dos indivíduos de cada nível trófico no início de cada rodada, e da construção do gráfico do número de indivíduos (eixo y) contra a variável tempo, que corresponde a rodadas do jogo ou gerações de vida (eixo x).

Mas, nesse caso específico, em meio à dinâmica do jogo, os alunos tiveram um insight e puderam vislumbrar o significado do equilíbrio dinâmico e a importância de não causar rupturas no equilíbrio entre as populações.

Como nos traz Volpato (2002, p. 224), "no seu brincar, a criança constrói e reconstrói simbolicamente sua realidade e recria o existente" e esse recriar no jogo facilita o estudante a memorizar diferentes conceitos e melhor entender diversos fenômenos, mecanismos e suas sequências (SABO, 2011). Corroborando com esta afirmação, estão os estudos de Humberto Maturana e Francisco Varela (1995), que conduziam a uma "biologia do amor", evidenciando a superação da visão dicotômica de mundo, separando corpo e alma, corpo e espírito, corpo e mente, ser humano e natureza, observador e observado, razão e emoção, e que impulsionaram novos estudos, como o de Maturana e Verden-Zöller (2011), que veem na democracia o resultado da boa relação entre a criança e a mãe, e apontam os malefícios decorrentes do distanciamento corporal e emocional entre a criança e o adulto. E aí está a grande colaboração de ambos, fazendo menção à importância do amar e do brincar e sobretudo do emocionar, a partir das experiências lúdicas, representadas pelo brincar. Seu papel na construção da verdadeira democracia, que se opõe à cultura que hoje propaga a dominação, a competição predatória, o desrespeito à diversidade biológica e cultural, entre outros. Vale ainda destacar Schwartz (2014, p. 60) que, ao definir atividade lúdica, a aponta como "forma primitiva de comunicação entre realidade e fantasia e uma forma de expressão de sentimentos prazerosos, que acompanham o ser humano ao longo de toda a sua existência”.

Nesta perspectiva, em que existe uma formação do ser humano de amanhã, mais do que simplesmente aprender conceitos, os alunos desenvolveram um sistema de valores entre eles - não foi uma construção e crescimento individual, isolado; foi algo que surgiu e se espalhou no coletivo. Esse contexto corrobora com as ideias de Clément (2006), de acordo com Guimarães et al. (2008, p. 82), que acreditam que "o conhecimento científico, os sistemas de valores e as práticas sociais interagem entre si, constituindo as concepções que os sujeitos têm sobre determinados assuntos". Isso porque, embora inicialmente gostassem de correr e se sentir capazes e realizados ao capturar seu alimento e serem bem-sucedidos naquela geração (rodada), e por isso estarem envolvidos emocionalmente no jogo, eles foram capazes de fazer o autossacrifício de morrer na rodada para manter o sistema vivo (lembrando que, ao iniciar a primeira rodada do jogo, nenhum dos alunos queria ser planta porque ficava parado e não tinha graça, pois a graça consistia em capturar o alimento e não ser imóvel para servir de alimento para as lebres). 
Mas sobre que tipo de valores podemos estar falando? Ou melhor, sobre que tipo de valores a EA, voltada para uma ecologia profunda, pode estar falando? E por que esse debate é tão importante?

A esse respeito, Fritjof Capra (2006, p. 28) relata:

Toda a questão dos valores é fundamental para a ecologia profunda; é, de fato, sua característica definidora central. Enquanto que o velho paradigma está baseado em valores antropocêntricos (centralizados no ser humano), a ecologia profunda está alicerçada em valores ecocêntricos (centralizados na Terra). É uma visão de mundo que reconhece o valor inerente da vida não-humana. Todos os seres vivos são membros de comunidades ecológicas ligadas umas às outras numa rede de interdependências. Quando essa percepção ecológica profunda torna-se parte de nossa consciência cotidiana, emerge um sistema de ética radicalmente novo.

Essa concepção, a qual envolve uma percepção ecológica profunda, já preconizada por Arne Naess (1990), caminha lado a lado ao que se pode chamar de educação ambiental profunda. Um exemplo dessa orientação se encontra na proposta metodológica Educação ambiental de corpo\&alma (RIBEIRO, 2005), a qual parte de uma concepção mais abrangente do termo ecologia, em que eco ou oikos (do grego) significa casa e logia, estudo. O que nos leva, portanto, ao estudo da casa (ou de um sistema) e ainda ao termo economia, no qual nomía significa "gestão", ou, gestão da casa ou de um sistema.

Para chegar a essa percepção mais profunda, a proposta inicia suas reflexões a partir das casas humanas mais íntimas, o corpo e a alma (psique), cuja dinâmica também é marcada pela interdependência e interinfluência, afetando os demais sistemas, a exemplo das relações sociais e com os demais ambientes especialmente marcados por valores e estados emocionais. Como lembra Ribeiro (2011), a EA, ao educar para valores e condutas pró-ambientais, ainda não tem como foco a causa de comportamentos insustentáveis, considerando que, na maioria dos casos, a consciência, a sensibilização, a motivação e o empoderamento ainda podem não ser suficientes como os caminhos para a formação de comportamentos sustentáveis. A possibilidade dessa visão profunda abre espaço para a busca da causa de comportamentos insustentáveis, a ser agora encontrada não apenas no mundo exterior, mas no que existe dentro de cada um e que, na maior parte dos casos, abriga a raiz dos comportamentos responsáveis pelos cenários com que deparamos, afinal, por trás das mazelas perpetradas pela humanidade e seus ambientes ou, suas casas ao longo da história, estavam valores não condizentes com o ideário de um mundo melhor.

\section{Um pouco mais além sobre o vislumbre do cenário de catástrofe}

Uma pergunta adicional que podemos fazer é se o grupo dos alunos que optaram por manter o equilíbrio do ecossistema teve a visão de que, se o alimento acabasse, haveria fome e isso significaria a morte da própria espécie? Essa hipótese se enquadra na apreensão dos conceitos envolvidos na Teoria de Gaia (LOVELOCK, 1972, 1991; MARGULIS; LOVELOCK 1974), em que a necessidade de equilíbrio no ecossistema é indispensável para a vida no planeta. Para esses autores, Gaia corresponde a um sistema vivo, com propriedades sistêmicas de retroalimentação e controle capazes de regular o clima e a química em um estado confortável para a vida.

De acordo com Lenton e Van Oijen (2002), Gaia, enquanto um sistema termodinâmico aberto, deve ser distinguido conceitualmente do sistema Terra e também da definição de biosfera, por se tratar de um sistema adaptativo complexo, cuja propriedade mais notável seja a presença permanente e em profusão de vida, em que a própria vida influencia as condições do planeta para além da influência local apresentada no conceito de biosfera. Para Capra (2006, p. 92), portanto, 
"o processo de auto-regulação é a chave da ideia de Lovelock". Mas haveria também, além dessa capacidade fisiológica, uma espécie de propriedade teleológica, pois parece dotada do objetivo inconsciente de promover essa mesma regulagem com vistas à manutenção da vida no planeta, ou seja, manter a si própria como um sistema vivo. Para Valadão et al. (2008), o desdobramento natural dessa teoria é o problema de equilibrar o meio ambiente, pois se não forem determinadas ações imediatas para conter o aumento da população humana, a degradação das terras, 0 esgotamento dos recursos naturais, o acúmulo de resíduos, todo tipo de poluição, a mudança climática, os abusos da tecnologia e a destruição da biodiversidade, podemos tornar essa situação de desequilíbrio irreversível, fato que acarretaria na destruição do planeta Terra. Nesse sentido, o grupo de alunos conseguiu, durante o jogo, distinguir entre a fome e a preservação dos seres e promoveu o equilíbrio das três espécies envolvidas na trama.

A questão crucial sobre essa hipótese (o grupo dos alunos optaram por manter o equilíbrio do ecossistema porque teve a visão de que, se o alimento acabasse haveria fome e isso significaria a morte da própria espécie) é que eles não tinham esse conhecimento prévio, quase instintivo, uma vez que a ciência vinculada à teoria do equilíbrio dinâmico seria desenvolvida posteriormente a partir dos dados numéricos do jogo que ainda estava em andamento.

Pode-se evidenciar, nesse caso, o que Capra (2006, p. 48) descreve: "Quando percebemos a realidade como uma rede de relações, nossas descrições também formam uma rede interconectada de concepções e de modelos". Isso também pode ser comparado ao modelo que Clément (2006) descreve. Esse modelo, intitulado KVP (K, do inglês knowledge - conhecimento; V, do inglês values - valores; e P, do inglês practices - práticas), propõe que todo sujeito humano constrói concepções que são determinadas não somente pelo conhecimento, mas também por suas práticas sociais e seus valores. Conectados como uma rede, os alunos, em sua individualidade, perceberam o sentido do desastre que poderia significar a ação de devorar todo o alimento, e transferiram da natureza para o jogo o conceito de valor à vida, a importância da preservação da espécie e do equilíbrio da cadeia alimentar. Ou talvez ainda o que Ornstein e Ehrlich (2010) apontaram como um caminho de identificação, consciência e compromisso ("empatia") com uma grande família planetária.

Como apontado anteriormente, o aprendizado pela experiência, a linguagem lúdica está entre os principais instrumentos, ao envolver os sistemas não lineares de aprendizagem, associando informações cognitivas e afetivas, ou seja, a razão, o conceito e a emoção a partir da exploração dos sentidos, do prazer. Consequentemente, há maior produção de neurotransmissores como a serotonina, sendo este um dos principais neurotransmissores que ajudam a cognição e o comportamento, juntamente com a dopamina, a norepinefrina e a acetilcolina (FERNANDES et al., 2015), facilitando a compreensão e a memorização de conceitos e associando o aprendizado a momentos de prazer. Contudo, há de se considerar que a linguagem lúdica também favorece o acesso à memória genética, uma vez que é uma forma primitiva de comunicação (SCHWARTZ, 2014), a qual, no caso da sobrevivência, pode despertar padrões em que a sensação de desprazer pode estar associada ao medo de extinção dos descendentes da sua espécie.

Ribeiro (2005) ilustra um caso do plantio de uma pimenteira, carregada de pimentinhas ainda em desenvolvimento, em que a planta que fora arrancada com as raízes tinha apenas a raiz pivotante intacta: ao ser replantada sem o desbaste dos seus ramos, esperava-se que ela pudesse poupar energia, que seria destinada à recuperação radicular e à sobrevivência do exemplar. Obviamente, entre a sobrevivência desse único exemplar e o desenvolvimento de inúmeros descendentes, a planta optou pela espécie, ou seja, ao investimento no cuidado com a descendência (quantidade), destinando nutrientes ao desenvolvimento das jovens pimentas (sementes). Observase que, tanto nas crianças quanto nas plantas, esse manual de sobrevivência está contido em seu 
DNA e pode ser acessado, mesmo quando tratamos com o imaginário, uma vez que o cérebro não distingue realidade da ficção, do imaginário. Esta afirmação pode ser confirmada a partir da compreensão, em primeiro lugar, do que é o medo. Derivado do latim timor, temor, medo pode ser considerado um "estado afetivo suscitado pela consciência do perigo ou que, ao contrário, suscita essa consciência (medo de um animal ao se sentir ameaçado)" (HOUAISS, 2001, p. 1879). É, portanto, uma reação orgânica diante de um motivo real ou imaginário (DAMÁSIO, 1996), mas que está relacionado à sobrevivência. Esse sentimento pode ser obtido a partir de um estimulo físico ou mental (caso da imaginação - jogos, filmes etc.), gerando uma resposta fisiológica no organismo, liberando hormônios do estresse como a adrenalina e o cortisol, cuja função está diretamente ligada ao sistema de luta ou fuga. Segundo Damásio (1996), eles preparam o corpo para estar alerta, forte e cuidadoso, pronto para lutar ou fugir e cujo papel, fugindo ou lutando, é a sobrevivência.

Outro aspecto central é que 10 segundos para vislumbrar todas essas interconexões é pouco tempo, o que reforça a ideia de possível mobilização de neurotransmissores por ocasião da atividade lúdica. Não estariam essas crianças vivenciando algo maior, para além do conceito, e exercitando memórias primitivas, as quais hoje são utilizadas de forma mais sutil e de maneira grupal? Neste caso, a questão nos remete a uma segunda hipótese: a da existência da ressonância mórfica de Sheldrake. Poderíamos ainda acrescentar aqui a necessidade de sobrevivência como também relacionada ao inconsciente coletivo de Jung (2012), uma vez que é baseado na camada mais profunda da psique humana, sendo constituído de imagens universais que existem desde os tempos mais remotos (JUNG, 2012). Ou estaríamos diante das duas hipóteses?

Como apontado anteriormente, embora esse comportamento pudesse ter origem no instinto de preservação da espécie, há de se destacar o papel das emoções conduzindo essas estratégias. Ornstein (1991) afirma haver um controle sem nossa consciência que se relaciona à evolução. No caso desse jogo, um estímulo emocional pode evocar uma das primeiras informações extraídas pela nossa herança animal, a de distinguir entre um estímulo prazeroso ou não-prazeroso, função do cérebro emocional (GUYTON; HALL, 2006; LEDOUX, 1998; PEÑA-CASANOVA, 2007). Segundo Cannon (1927), esse estímulo ameaçador produz, em primeiro lugar, um sentimento de medo, desencadeando posteriormente no indivíduo reações físicas, as quais, por sua vez, são associadas ao desprazer.

Nesse caso, a sobrevivência estaria relacionada não apenas à perpetuação da espécie a partir de uma memória ancestral, mas poderia ter ganhado complexidade ao longo da evolução humana, envolvendo valores que conduziram a consciência de sobrevivência agora em nível planetário. Segundo Migliori (2013), há uma profunda relação entre a evolução da nossa espécie, o cérebro e o comportamento, e muito menos entre educação e evolução da espécie. Isso não significa diminuir a importância da educação, mas entendê-la num contexto macro e reconhecer que ela modela os cérebros, colocando na educação um grau a mais de responsabilidade.

Assim, os alunos, com base apenas na experiência do jogo, sem terem desenvolvido primeiramente o conceito em aula, foram capazes de entender que "aquilo que denominamos parte é apenas um padrão numa teia inseparável de relações. Portanto, a mudança das partes para o todo também pode ser vista de uma mudança de objetos para relações" (CAPRA, 2006, p. 47). Talvez isso represente a sintonia com campos mórficos de Sheldrake (1998), em que esse conhecimento da interdependência e do papel de cada um na manutenção do equilíbrio tenha aflorado nessas crianças.

E mais do que isso, desenvolveram um novo conjunto de valores, em que sacrificar-se individualmente em prol da coletividade passou a ser um novo valor ético que despontava no conceito coletivo, o que valeu, posteriormente, um debate em sala de aula acerca dessa construção 
de conceitos. Ou seja, tal como programas de ecoturismo bem desenhados, que na visão de Forestell (1993, p. 278, tradução nossa), "estão em posição de contrariar uma visão mecanicista e despersonalizada da natureza com uma demonstração do planeta como organismo vivo", o jogo também pode promover esse resultado.

\section{A ressonância mórfica entre os alunos}

Na segunda hipótese, o fato de o grupo ter escolhido não capturar sua presa pode ser um exemplo do que Sheldrake (1998) define como ressonância mórfica. A ressonância causa "a influência do semelhante sobre o semelhante através do tempo e do espaço", e não diminui com a distância física. Interessante comentar que ela não transfere a energia de um ser para outro, mas sim a informação, sugerindo como organizar a energia. Para esse autor, a ressonância mórfica implica uma espécie de ação à distância no espaço e no tempo. Na teoria morfogenética, o passado influi no presente. Os ancestrais influem na geração atual por um efeito de ressonância.

Segundo o autor, "[...] A forma e o comportamento dos organismos não são, simplesmente, os produtos de interações mecânicas no seio do organismo, ou entre o organismo e o seu ambiente imediato; dependem, também, dos campos com os quais o organismo está sintonizado" (SHELDRAKE, 1998, p. 195). Os campos seriam estruturas de probabilidade, nas quais as influências dos tipos passados mais comuns se combinam para aumentar a probabilidade de repetição desses mesmos tipos (SHELDRAKE, 1998, p. 159). Conforme relatado na experiência em sala de aula, o grupo de alunos não foi induzido, antes da atividade, a pensar na sua própria sobrevivência (esta, do coletivo de seres vivos, e não do indivíduo isoladamente), mas essa ideia pareceu óbvia diante da situação apresentada, o que poderia denotar uma reação que já tinha sido adotada pelos seus antepassados. Assim sendo, pode-se sugerir a existência da memória coletiva e inconsciente de sobrevivência entre as diferentes populações da mesma espécie e, do conjunto de diferentes espécies interligadas, pode ter sido configurada. Isso fez com que formas e hábitos fossem transmitidos de geração para geração.

A ideia de Sheldrake permite compreender que os processos regulares da natureza são governados, em alguns casos, por hábitos herdados por meio da ressonância mórfica, e não apenas pelas leis eternas como se pensava. Dessa maneira, tem-se que os organismos vivos herdam não só genes, como também os campos mórficos ou auras.

Os genes são transferidos materialmente por seus ancestrais, e permitem produzir certos tipos de moléculas de proteínas; os campos mórficos são herdados de um modo não material, por ressonância mórfica, não apenas de ancestrais diretos, mas também de outros membros da espécie. O organismo sintoniza os campos mórficos da sua espécie e, desse modo, tem à sua disposição uma memória coletiva ou de grupo onde colhe informações para seu desenvolvimento (SHELDRAKE, 1993, p. 116).

A memória no seio dos campos mórficos é cumulativa e é essa a razão pela qual todas as espécies de fenômenos se tornam cada vez mais habituais por repetição. A busca da sobrevivência coletiva da biodiversidade e a manutenção do equilíbrio dinâmico no planeta também fariam parte dessa memória coletiva, e retomaria então as ideias de Margulis e Lovelock (1974) sobre a teleologia em Gaia.

Um aspecto adicional deve ser analisado: os alunos nem conversaram entre si, pois não havia tempo durante uma rodada de 10 segundos, e mesmo assim a ação de interromper a predação emergiu quase que simultaneamente em várias crianças em diferentes pontos do local do jogo. Portanto, além da memória coletiva, o pertencimento a um mesmo campo mórfico pode ser a explicação para o compartilhamento quase instantâneo e simultâneo de valores emergidos durante 
o jogo e o reconhecimento da necessidade de sacrificar-se em prol da sobrevivência da espécie que encarnavam na brincadeira.

Assim, podemos cogitar uma terceira situação ou hipótese, em que o pensamento segundo as duas vertentes pode ter ocorrido concomitantemente. Essa combinação das duas primeiras hipóteses também faz sentido, uma vez que ambas as teorias possuem o link com a Mãe Natureza e sua história. Dessa forma, podemos dizer que a situação apresentada no decorrer da atividade e a conclusão de que a extinção do alimento provocaria a própria eliminação da espécie, além da necessidade de evitar tal situação, possui característica das duas hipóteses citadas, que foram compartilhadas/disseminadas instantaneamente por meio da ressonância do campo mórfico.

O jogo, por sua vez, proporcionou o conhecimento empírico dos alunos, vivenciando uma consciência do problema que poderia causar, caso fossem devorar todo o seu alimento. A consciência demonstrada na atividade condiz com uma situação de emergência de um novo tipo de valor social: o compromisso com a sustentabilidade de vida no planeta. Entre os autores que buscam obter essa nova visão de mundo, Sheldrake (1993) e Forestell (1993) defenderam que a experiência direta de contato com a observação da natureza permitiria desenvolver uma compreensão prática e intuitiva para além da cognitiva ou intelectual. Nesse sentido, o processo de aprendizagem a partir dessas experiências pode reafirmar a importância da didática não linear (ou afetivo, experiencial), uma vez que é a dupla conhecimento-experiência, quando integradas, a grande responsável pela mudança de valores e atitudes, reafirmando que os princípios e as avaliações pertencem à dimensão da afetividade (PIAGET, 1972). A nossa experiência permite dizer, que além dessa experiência direta de contato e observação, o jogo também pode promover o desenvolvimento de uma nova consciência, pela mobilização de sentimentos e percepções.

Essa nova consciência poderia representar o que Sheldrake (2013) chama de emergência de um ser consciente transcendente, em que este se vê parte do universo e de tudo o que nele existe: "A integralidade mais ou menos limitada dos organismos em todos os níveis de complexidade seria visto como um reflexo da unidade transcendente da qual dependem e da qual derivam, em última análise" (SHELDRAKE, 2013, p. 227).

Nesse contexto, o novo compromisso, ou a nova consciência, permite refletir inclusive sobre a possibilidade de abrir mão de conquistas individuais (ganhar na rodada, capturar o alimento, ou quem sabe, evoluir para a consciência de consumir menos, contrariando os ditames do mercado). São possibilidades que uma EA pode apresentar, articulando conhecimentos, valores e atitudes.

Esse olhar para o interior vem despertando mais e mais a curiosidade de atores dos mais diversos setores, mundo afora. Trinta anos de evolução científica podem representar, assim, percepções mais amplas e mais articuladas. Representam um considerável avanço, não apenas científico, mas para o próprio estado da arte da EA.

\section{Considerações finais}

O jogo e as brincadeiras fazem parte da essência da criança. Utilizar essas ferramentas no cotidiano escolar possibilita a produção do conhecimento, da aprendizagem e do desenvolvimento do jovem, bem como promove o prazer em aprender. A experiência relatada demonstrou que a imersão em um jogo pode despertar nas crianças, pela interação, reciprocidade e sentido de coletividade, valores ambientais importantes nesse momento de crescente degradação do meio ambiente. A esse respeito, considerando que os jovens tenham trabalhado a inteligência e as emoções em favor da sobrevivência do sistema, vale questionar se na sociedade humana fazemos ou faríamos isso. 
Algumas perguntas passam a ocupar nossas mentes: o que é necessário? Que valores nos falta desenvolver? Qual o papel da mudança individual dentro de um sistema social? Nesse sentido, qual o papel do educador? E das práticas pedagógicas de caráter lúdico, como o jogo? O jogo pode promover insights sobre conceitos e processos na natureza, que podem ser decorrência da memória coletiva impregnada por ressonância mórfica. Finalmente, cabe dizer que a experiência aponta para a importância de buscar novas estratégias educacionais que possam melhor cumprir os objetivos traçados pela PNEA, sobretudo no que se refere ao desenvolvimento de valores associados à promoção de conhecimentos e atitudes.

\section{Referências}

BRASIL. Lei 9.795, de 27 de abril de 1999. Institui a Política Nacional de Educação Ambiental e dá outras providências. Diário Oficial da União de 28/04/1999.

CADUTO, M. J. A guide on environmental values education. Paris: Unesco, 1985.

CANNON, W. B. The James-Lange theory of emotion: a critical examination and an alternative theory. American Journal of Psychology, Champaign, v. 39, n. 1, p. 10-124, 1927.

CAPRA, F. A teia da vida: uma nova compreensão científica dos sistemas vivos. São Paulo: Cultrix, 2006.

CLÉMENT, P. Didactic transposition and KVP model: conceptions as interactions between scientific knowledge, values and social practices. Braga: Esera Summer School, 2006.

DAMÁSIO, A. O Erro de Descartes: emoção, razão e o cérebro humano. São Paulo: Companhia das Letras, 1996.

FERNANDES, C. T. et al. Possibilidades de aprendizagem: reflexões sobre neurociência do aprendizado, motricidade e dificuldades de aprendizagem em cálculo em escolares entre sete e 12 anos. Ciência \& Educação, Bauru, v. 21, n. 2, p. 395-416, 2015.

FORESTELL, P. H. If Leviathan has a face, does Gaia have a soul?: incorporating environmental education in marine eco-tourism programs. Ocean \& Coastal Management, Amsterdam, v. 20, $\mathrm{n}$. 3, p. 267-282, 1993.

GUIMARÃES, M. D. M. et al. A Teoria Gaia é um conteúdo legítimo no ensino médio de Ciências? Pesquisa em Educação Ambiental, São Carlos, v. 3, n. 1, p. 73-104, 2008.

GUYTON, A. C.; HALL, J. E. Tratado de fisiologia médica. Rio de Janeiro: Elsevier Brasil, 2006.

HOUAISS, A. Dicionário Houaiss de Língua Portuguesa. Rio de Janeiro: Objetiva, 2001.

JUNG, C. G. Os arquétipos e o inconsciente coletivo, vol. 9/1. Petrópolis: Vozes, 2012.

KRASILCHIK, M. Prática de ensino de biologia. São Paulo: Harper \& Row do Brasil, 1983. 
LEDOUX, J. O cérebro emocional: os misteriosos alicerces da vida emocional. São Paulo: Objetiva, 1998.

LENTON, T. M.; VAN OIJEN, M. Gaia as a complex adaptive system. Biological Science, London, v. 357, n. 1421, p. 683-695, 2002.

LEWIS, E.; MANSFIELD, C.; BAUDAINS, C. Getting down and dirty: values in education for sustainability. Issues in Educational Research, Sidney, v. 18, n. 2, p. 138-155, 2008.

LOVELOCK, J. Gaia as seen through the atmosphere. Atmospheric Environment, Amsterdam, v. 6, n. 8, p. 579-580, 1972.

LOVELOCK, J. As eras de Gaia. Rio de Janeiro: Campus, 1991.

MARGULIS, L.; LOVELOCK, J. Biological modulation of the Earth's atmosphere. Icarus, Amsterdam, v. 21, n. 4, p. 471-489, 1974.

MATURANA, Humberto R.; VARELA G., Francisco. A árvore do conhecimento: as bases biológicas do entendimento humano. São Paulo: Editora Psy II, 1995.

MATURANA, H.; VERDEN-ZÖLLER, G. Amar e brincar - fundamentos esquecidos do humano. São Paulo: Palas Athena, 2011.

MIGLIORI, R. Neurociências e educação. São Paulo: Brasil Sustentável, 2013.

NAESS, A. Ecology, community and lifestyle: outline of an ecosophy. Cambridge: Cambridge University Press, 1990.

ORNSTEIN, R. A evolução da consciência: de Darwin a Freud, a origem e os fundamentos da mente. São Paulo: Best Seller, 1991.

ORNSTEIN, R.; EHRLICH P. Humanity on a tightrope: thoughts on empathy, family, and big changes for a viable future. Lanham: Rowman \& Littlefield Publishers, 2010.

PEDRO, A. P. Ética, moral, axiologia e valores: confusões e ambiguidades em torno de um conceito comum. Kriterion: Revista de Filosofia, Belo Horizonte, v. 55, n. 130, p. 483-498, 2014.

PEÑA-CASANOVA, J. Neurología de la conducta y neuropsicología. Buenos Aires: Médica Panamericana, 2007.

PIAGET, J. Psicologia e pedagogia. Rio de Janeiro: Forense, 1972.

RIBEIRO, I. C. Educação ambiental de corpo\&alma: trabalhando sentimentos e valores numa experiência com Agenda 21 Escolar. Ribeirão Preto: São Francisco, 2005. 
RIBEIRO, I. C. Educação Ambiental de Corpo\&Alma. In: Educação Ambiental no mundo globalizado: uma ecologia de riscos, desafios e resistências. João Pessoa: Editora Universitária UFPB, 2011, p. 39-64.

RIBEIRO, I. C. Educação para a vida. Rio Claro; Setúbal: Felicidade Sustentável, 2018. Disponível em: <http://bit.ly/educacaoparaavida〉. Acesso em: 23 ago. 2018.

RIBEIRO, I. C.; SCHWARTZ, G. M. Valores em transformação: por uma felicidade sustentável. São Paulo: Garcia Ediziones, 2017.

SABO, M. H. Children, teaching and modern science. Present Environment and Sustainable Development, Iasi, v. 5, n.1, p. 215-220, 2011.

SAITO, C. H.; GOMES, M. R.; ALMEIDA, L. E. Does a baconian vision of nature dominate among researchers in ecology? A case study in an ecological reserve of the IBGE in Central Brazil. Human Ecology, New York, v. 39, n. 6, p. 835-839, 2011.

SCHWARTZ, G. M. Atividade lúdica. In: GONZÁLES, F. J.; FENSTERSEIFER, P. E. (Org.). Dicionário crítico de educação física. Ijuí: Unijuí, 2014. p. 59-60.

SHELDRAKE, R. O renascimento da natureza: o reflorescimento da Ciência e de Deus. São Paulo: Cultrix, 1993.

SHELDRAKE, R. A ressonância mórfica e a presença do passado: os hábitos da natureza. São Paulo: Crença e Razão, 1998.

SHELDRAKE, R. Uma nova ciência da vida: a hipótese da causação formativa e os problemas não resolvidos da Biologia. São Paulo: Cultrix, 2013.

TAVARES, C.; FREIRE, I. M. "Lugar do lixo é no lixo": estudo da assimilação da informação. Ciência da Informação, Brasília, v. 32, n. 2, p. 125-135, 2003.

UNESCO. Intergovernmental Conference on Environmental Education. Tbilsi (USSR), UNESCO, Paris, 1978.

VALADÃO, A. F. C. et al. Teoria de Gaia e a preservação do meio ambiente. Gestão $e$ Conhecimento, Poços de Caldas, v. 4, n. 2, p. 1-8, 2008.

VOLPATO, G. Jogo e brinquedo: reflexões a partir da teoria crítica. Educação \& Sociedade, Campinas, v. 23, n. 81, p. 217-226, 2002. 